THE LEGITIMACY OF INEQUALITY:

InTEgrating The Perspectives of System Justification AND Social JUdGMENT

\author{
Patrick Haack \\ (Corresponding author) \\ University of Lausanne \\ patrick.haack@unil.ch \\ Jost Sieweke \\ Vrije Universiteit Amsterdam \\ j.sieweke@vu.nl \\ Post-print version of forthcoming article in the Journal of Management Studies \\ (DOI: 10.1111/joms.12323).
}

Acknowledgements: Both authors contributed equally to this manuscript. We thank John Antonakis, Santi Furnari, Vern Glaser, Moritz Gruban, Lianne Lefsrud, Emilio Marti, Mike Pfarrer, Kris-Stella Trump, Jean-Philippe Vergne, Tyler Wry, as well as the special issue editors and three anonymous reviewers for insightful comments and suggestions on previous drafts. During the completion of the paper we also benefitted from discussions at research seminars at Cass Business School and the Vrije Universiteit Amsterdam. Furthermore, we are grateful for helpful feedback at the 2015 German Organization Studies Colloquium (WK-ORG) and the 2014 Workshop on New Institutionalism. 


\title{
THE LEGITIMACY OF INEQUALITY:
}

InTEgrating The Perspectives of System Justification AND Social JudgMENT

\begin{abstract}
To explain the legitimation of inequality among the members of a social system, we blend system justification theory and the theory of social judgment. We identify adaptation and replacement as two major mechanisms of inequality legitimation and examine their influence in the unique setting of a natural experiment, the reunification of socialist East Germany and capitalist West Germany. We show that the new members of a society in which inequality is broadly endorsed and perceived as enduring will adapt to this perception and come to view inequality as acceptable. This process of adaptation reflects the subtle but powerful influence of collective legitimacy on an individual's tacit approval of inequality. Inequality also becomes legitimate as older cohorts are replaced by younger cohorts; however, this effect is weaker than the effect of adaptation. We contribute to the literature by demonstrating that developing and testing a theory of how inequality becomes legitimized can provide new insights into the ideational antecedents of inequality.
\end{abstract}

Keywords: inequality, legitimacy, natural experiment, system justification, social judgment 
During the 2016 World Economic Forum in Davos, Oxfam executive Mark Goldring complained that it "is simply unacceptable that the poorest half of the world population owns no more than a small group of the global super-rich - so few, you could fit them all on a single coach” (The Guardian, 2016). Goldring was referring to an Oxfam report revealing that the world's 62 richest people owned as much wealth as the poorest half of the world's population (The Guardian, 2016). This comment and the report that inspired it highlight the huge gap between the few "haves" and the many "have-nots."

Despite the detrimental impacts of social and economic inequality — including poor health (Pickett and Wilkinson, 2015), lower levels of happiness (Alesina et al., 2004), and slower economic growth (Halter et al., 2014) — there has been hardly any noteworthy action to remedy the causes of this trend. Although such action would arguably be in the interest of the large majority of disadvantaged people (Jost et al., 2004), the public discourse typically sidesteps the topic of inequality, and there is evidence that the general public shows little concern for inequality (Luttig, 2013). Thus, in blatant opposition to Goldring's statement, inequality seems to be perceived as acceptable, even to those who are disadvantaged by the status quo. The absence of popular resistance to social and economic inequality poses a puzzle, because it violates the idea that people demand the redistribution of wealth to maximize their self-interest (Trump, 2017) and is at odds with findings that individuals care deeply about norms of justice and fairness (Greenberg, 2010; Greenberg and Colquitt, 2005).

What might explain the tacit approval of the current system, which promotes the preservation of inequality and other forms of social dominance? According to system justification theory (Jost and Banaji, 1994; Jost et al., 2015), many members of a social system tend to preserve the belief that existing social arrangements are fair, legitimate, justifiable, and necessary. This belief allows them to satisfy basic psychological needs, such as the need to maintain a positive self-image and to believe the world is just. Believing in the legitimacy of a social system, in turn, disposes people to support that system (Stryker, 1994; Zelditch, 2001a). 
Thus, the psychological need to justify a system that is perceived as legitimate typically leads members of that system to defend and perpetuate the social and economic forms of inequality that characterize it.

In this paper, we take a fresh look at the legitimation of inequality by integrating the perspective of system justification with the perspective of social judgment, which originates in organization and management studies (Bitektine, 2011; Bitektine and Haack, 2015; Haack et al., 2014; Huy et al., 2014; Tost, 2011). Specifically, we develop and test a novel theory on how inequality becomes accepted among the members of a social system and turns into a taken-for-granted and self-perpetuating feature of everyday life (Amis et al., 2017). We define “inequality” as the uneven distribution of economic resources, such as income and wealth, as well as of other social resources, such as information and social integration, which contribute to income or wealth as intervening variables.

System justification theory proposes that legitimacy, and by extension the legitimation of social inequality (Costa-Lopes et al., 2013), can be viewed as a psychological construct (Jost and Major, 2001; Tyler, 2006). This stream of research focuses on legitimacy beliefs and on the personal and situational contingencies that influence such beliefs and lead the members of a system to justify them. However, to date few studies adopting the system justification perspective have examined how approval and conformity at the individual level emerge from personal beliefs that derive from the legitimacy beliefs that other members of a group hold. In contrast, the perspective of social judgment argues that legitimacy can be viewed as an ongoing process of judgment formation. The proponents of this perspective assume that this process is multi-level, in the sense that legitimacy judgments occur simultaneously at the collective level (where perceptions of appropriateness are created, shared, and validated) and at the level of the individual, who uses collective perceptions to derive his or her judgment and engage in appropriate action (Bitektine and Haack, 2015; Johnson et al., 2006). 
Blending the perspectives of system justification and social judgment allows us to theorize that in social systems where inequality is (perceived to be) high but widely accepted, the members of those systems are likely to regard inequality as acceptable, as a result of a process of adaptation. In this view, the "validity belief" about inequality-that is, the belief that inequality objectively exists and is approved collectively by the members of a social groupgenerates and supports “propriety beliefs” about inequality—-that is, an individual's acceptance of inequality. Social systems that are considered valid thus have a bolstering effect on beliefs about propriety (Zelditch, 2001b). The context of inequality naturally leads to an understanding of propriety as acceptability, meaning that a legitimacy object does not require explicit support (“strong validation”) but can maintain propriety as long it is not questioned or challenged (“weak validation”) (Johnson et al., 2006).

Taking into account that individuals may not adapt to the perceived consensus in a social system and instead remain committed to their previous beliefs (Tilcsik, 2010), we further theorize that changes in legitimacy beliefs may be also driven by the process of replacement (Ryder, 1965), through which younger cohorts replace older cohorts. Because each cohort grows up in a unique historical context, the members of different cohorts often hold different values and beliefs. Thus, we may assume that the members of a society who believe in the legitimacy of inequality come to substitute members who dispute the legitimacy of inequality, as the latter quit the social system (mainly because of death, but also due to relocation). In this view, differences between outgoing and incoming cohorts may explain changes in legitimacy beliefs (King, 2011).

We test our theory in the context of the German reunification, the process through which the socialist German Democratic Republic (GDR; also referred to as “East Germany”) joined the capitalist Federal Republic of Germany (FRG; also referred to as "West Germany”) to form a united Germany. The case of the German reunification lends itself to our theorybuilding exercise because it resembles a "natural experiment," in which exposure to the 
treatment and control conditions is determined by factors outside the control of the researcher. Specifically, the former citizens of the GDR can be regarded as the treatment group, because they experienced the transition from a socialist system (which placed great emphasis on equality) to a capitalist system (in which inequalities were regarded as legitimate; (van der Toorn et al., 2010). The citizens of the FRG can be regarded as the control group, because they did not experience this transition. The case of East Germany is of broad interest, because there are other countries (e.g., China and Cuba) that may experience a similar transition from socialism to a free-market economy in the near future.

This paper's contribution is fourfold. First, we advance our understanding of the ideational and social dynamics of inequality legitimation by complementing the theory of system justification, which focuses on the individual level and treats legitimacy as a state, with the theory of social judgment, which views legitimacy as a multi-level processual phenomenon. This study supports empirically the view that we develop; namely, that inequality becomes accepted among members of a social system through processes of adaptation and replacement. Second, we add to theories of legitimacy from the social judgment perspective by empirically demonstrating the subtle but powerful influence of collective-level or "generalized” perceptions of legitimacy on an individual's approval and consent. Extant research on the formation of social judgments leans towards theory development, and much of the scholarship on legitimacy is "highly theoretical, invoking legitimacy as an explanatory concept rather than examining it as an empirical attribute” (Deephouse and Suchman, 2008, p. 49). Thus, we believe that our study, which engages in the empirical analysis of legitimacy as a dependent variable and a phenomenon in its own right, makes a timely contribution to research on legitimacy. Third, we contribute to the development of a microfoundational agenda in research on institutions and inequality (Amis et al., 2017). Unlike other theoretical perspectives in management studies (Felin et al., 2015), institutional theory has paid little attention to the microfoundations of institutions (Sieweke, 2014), despite calls for further inquiry into this topic (Cornelissen et 
al., 2015; Powell and Colyvas, 2008). Our study emphasizes that, in order to study the microfoundations of inequality legitimation, research must go beyond micro-level explanations and seek the links between the micro-level and macro-level structures and outcomes (Bitektine and Haack, 2015). Finally, our theory has implications for the study of management and organizations in general, particularly for research on consequences of inequality in organizations (e.g., Bloom and Michel, 2002) and for research on organizational justice (e.g., Greenberg and Colquitt, 2005).

\section{THE LEGITIMACY OF INEQUALITY}

The legitimacy of inequality can be examined from several perspectives (e.g., Jost and Major, 2001). In the present paper, we focus on two approaches that we consider particularly promising: the perspective of system justification and the perspective of social judgment. System justification theory suggests that social outcomes (including social and economic inequality) are perceived as legitimate because the members of a social system are motivated to think of their system as fair, just, and desirable. In turn, social judgment theory argues that legitimacy objects are perceived as legitimate either because members of the system approve of these objects or because they recognize and consent to the widespread approval of these objects. Legitimacy objects include properties that characterize a social system, such as inequality. In the following section, we compare both bodies of literature to develop an integrated theory of how inequality is legitimized among the members of a social system. Our guiding assumption is that, in order to understand the ideational antecedents of the material fact of inequality, it is necessary to develop and test a theory of legitimation (Della-Fave, 1986).

\section{The System Justification Perspective}

System justification theory aims to explain how, when, and why the members of a social system support the status quo (e.g., various forms of inequality), even if they are disadvantaged as a result (Jost and Banaji, 1994; Jost et al., 2004). This theory suggests that individuals are motivated to hold favorable beliefs about the legitimacy of the social system in which 
they live and work, due to the basic psychological need to believe the social system is fair and to maintain a positive self-image. For the advantaged members of a system, justifying that system as legitimate simply reflects the ideological promotion and rationalization of a good situation; for disadvantaged members, justifying the system prevents feelings of frustration and reduces the mental harm associated with being part of a system that is contrary to their self-interest (Jost et al., 2015; Jost and Hunyady, 2005).

Justifying the system fosters the legitimation of inequality and thus perpetuates both inequality and other forms of social dominance. Several studies supporting the predictions of system justification theory have identified personal and situational contingencies that influence the degree to which individuals justify the system to which they belong (Kay and Friesen, 2011). For instance, research has found that individuals perceive a system to be more legitimate if it is durable (e.g., Blanchar and Eidelman, 2013), stable (e.g., Laurin et al., 2013), or difficult to escape (e.g., Kay et al., 2009b).

Regarding personal factors, research shows, counter-intuitively, that disadvantaged individuals, such as people with a low income, are more likely to support the status quo and to justify inequality than advantaged individuals are (Jost et al., 2003c). Furthermore, the political orientations of individuals, as well as cognitive factors such as tolerance of ambiguity and openness to experience, are related to the degree to which people justify the system to which they belong (Jost et al., 2003b; Kay et al., 2009a).

System justification theory focuses on legitimacy at the level of individuals and conceptualizes it as an attitudinal construct and a relatively stable state. The emphasis on stability may stem from the fact that research has mostly analyzed justification beliefs in the context of systems that have achieved a high degree of institutionalization, such as the free-market economy in industrialized countries (Jost et al., 2003a). It may also reflect the cross-sectional study designs that much of this stream of research has employed to analyze system justification and legitimacy at a given point in time. Consequently, system justification theory offers 
few insights into the social dynamics that underlie the legitimacy judgments that individuals make. For that reason, we turn to the social judgment perspective.

\section{The Social Judgment Perspective}

In organization studies, legitimacy is commonly defined as a "generalized perception or assumption that the actions of an entity are desirable, proper, or appropriate within some socially constructed system of norms, values, beliefs, and definitions” (Suchman, 1995, p. 574). Legitimacy has been largely conceptualized as a perceptual phenomenon (Suchman, 1995); in other words, legitimacy is in "the eye of the beholder" (Ashforth and Gibbs, 1990, p. 177). On those grounds, researchers have drawn on cognitive and social psychology (e.g., Sherif and Hovland, 1961) and micro-sociology (e.g., Walker et al., 1986) to develop a theory of the inter-subjective and perceptual processes that underlie legitimacy judgments (Bitektine, 2011; Bitektine and Haack, 2015; Haack et al., 2014; Huy et al., 2014; Tost, 2011). From the perspective of the resulting theory of social judgment, the focal object of legitimation can be any behavioral pattern that occurs within an organization or social systems. This "pattern” might be, among other things, a rule, an organization, or a system of inequality (Johnson, 2004, p. 10-11).

The legitimacy construct has become prominent in organization studies and, in particular, in institutional theory (Deephouse et al., 2017). Many scholars, however, rely on Suchman’s (1995) rather broad definition of legitimacy, without specifying what particular aspect of legitimacy they are examining (Deephouse et al., 2017; Suddaby et al., 2017). Scholars who apply the social judgment perspective have stressed that it is important to refine the meaning of legitimacy while, at the same time, conserving the concept's inherently multifaceted nature. In these scholars' view, legitimacy is an intricate social process comprising three perceptual components: validity, validity beliefs and propriety beliefs.

Validity refers to the construal of appropriateness at the collective level (i.e., by a group as a whole). An important aspect of validity is that it exists objectively as a social fact and in- 
dependently of the opinion of a single individual. This objectified part of legitimacy enters the cognition of individuals as a "validity cue," which they can use to form a validity belief. A validity belief can be described as an individual's judgment that a legitimacy object is perceived as appropriate by others in a collectivity of individuals, independently of whether the focal individual regards that object as legitimate (Bitektine and Haack, 2015). The term propriety belief refers to an individual's private endorsement of a legitimacy object and his or her assessment of the appropriateness or acceptability of that object (Suddaby et al., 2017). ${ }^{\mathrm{i}}$

Suchman's (1995) seminal definition of legitimacy focuses on the aspect of validity and thus describes legitimacy primarily at the collective level (Zelditch, 2004). However, that definition does not sufficiently take into account propriety and validity beliefs and therefore does not adequately describe legitimacy at the individual level. In contrast, scholars in the social judgment tradition try to focus more closely on a specific aspect of legitimacy. In line with this approach, we aim to focus on propriety beliefs, which will serve as our key outcome variable, but we will also consider validity beliefs, which will serve as an important context variable.

According to the social judgment perspective, a legitimacy object is perceived as valid if it observably governs the views and actions of the authorities and of one's peers (Johnson et al., 2006). Individuals who do not privately endorse that object as proper may nevertheless believe that others perceive it as appropriate and therefore tacitly approve its behavioral prescriptions. If an individual's propriety beliefs are incongruent with his or her validity beliefs, that individual may suppress the former and act upon the latter (Bitektine and Haack, 2015). Over time, individuals tend to adjust their propriety beliefs so that they are congruent with the prevalent validity beliefs in the broader group to which they belong; in other words, validity beliefs may influence propriety beliefs (Walker et al., 1986; Yoon and Thye, 2011; Zelditch and Walker, 1984). A legitimacy object can acquire propriety and retain this quality so long as it is neither questioned nor challenged (“weak validation”). Thus, explicit support or approval 
(“strong validation”) is not always necessary for propriety. In this paper we posit that, in order for inequality to acquire propriety, even weak validation and tacit approval by a majority of individuals is sufficient. Individuals are unlikely to support inequality actively and enthusiastically, but they are likely to accept it passively (Berger and Luckmann, 1967).

To conclude, the perspective of social judgment posits that legitimacy judgments occur simultaneously at the collective level, where perceptions of appropriateness are created, shared, and typified (and thus generate validity), and at the level of individuals, who derive personal judgments (i.e., validity and propriety beliefs) from those collective perceptions and then engage in appropriate action, such as resisting or complying with a social system. Importantly, because individuals grant valid legitimacy objects the status of objective, natural, and inevitable facts, validity beliefs lead them to recognize a specific normative order as binding, which in turn fosters behavioral consent (Stryker, 1994).

\section{Towards the Integration of the Two Theories}

While system justification theory has identified the psychological underpinnings of legitimacy (Jost and Major, 2001; Tyler, 2006) and advanced a social psychological perspective on the legitimation of social inequality (Costa-Lopes et al., 2013), it has yet to acknowledge that individuals and their propriety beliefs are influenced by validity cues as signals of generalized perceptions of legitimacy (Suchman, 1995; Tost, 2011). Furthermore, system justification theory tends to take an essentialist view of legitimacy, which it conceptualizes as a state or enduring property of a social system.

By contrast, according to the theory of social judgment, the constituent components of legitimacy are not fixed or static, but dynamic and in flux. This suggests that beliefs about the legitimacy of inequalities can become institutionalized or deinstitutionalized among the members of a social system over time, in the sense that they constitute a widely accepted and unquestioned feature of "how things are” and "how things are done” (Berger and Luckmann, 1967). 
Moreover, the theory of social judgment argues that legitimacy cannot be reduced to a merely psychological construct but, rather, involves both individual-level and collective-level components, which are interdependent and mutually reinforcing. This crucial difference shows that, although both approaches to legitimacy concentrate on similar phenomenanamely, what motivates people to form legitimacy beliefs and the factors and processes through which such beliefs are formed—-they make different assumptions about the ontological status of legitimacy and focus on different levels of analysis. Specifically, system justification theory perceives legitimacy as a state and focuses on beliefs formed at the level of individuals, whereas social judgment theory perceives legitimacy as a process that takes place on multiple levels. Notwithstanding these differences, we suggest that the common ground that these two perspectives share allows for their theoretical integration (Okhuysen and Bonardi, 2011). Moreover, we argue that they are complementary and, as we will discuss below, that combining them helps us to gain further insight into the mechanisms that preserve social and economic inequality.

More specifically, system justification theory can be enriched by the view that individual beliefs about legitimacy accrue through processes of social interaction and collective-level construal of legitimacy, which is central to the theory of social judgment and highlights the inherently contextual foundation of legitimacy. Similarly, the temporal dimension of legitimacy, which is also central to the theory of social judgment, broadens the narrower scope of the system justification theory. In turn, the social judgment approach, which hardly examines the perceptual antecedents of individual-level judgments of legitimacy, can benefit from incorporating insights from social psychology on system justification. Furthermore, the primarily conceptual contributions to the literature on social judgment theory (e.g., Bitektine, 2011; Tost, 2011) can benefit from the depth and rigor of the empirical research that underpins the system justification theory, because the legitimacy construct in system justification resembles the concept of propriety belief in the social judgment perspective. Finally, in the context of 
our study, the insights into inequality that system justification theory provides help us to refine the general scope of social judgment theory. Overall, blending the two perspectives offers an opportunity to develop a comprehensive and useful theory of the inter-subjective processes of perception, interpretation, and interactions that are constitutive of the material antecedents and outcomes of inequality.

\section{THEORY DEVELOPMENT AND HYPOTHESES}

In the following section, we build on research on social change (e.g., Alesina and Fuchs-Schündeln, 2007; Ryder, 1965) and theorize two major mechanisms that may underlie the legitimation of inequality-adaptation and replacement. The process that these mechanisms support and through which inequality may acquire legitimacy in the eyes of individuals is what we call the "legitimation of inequality."

\section{Adaptation}

A first mechanism that may facilitate the legitimation of inequality is adaptation. Through this process, people adapt their values and standards to what they perceive as the established and valid norms of society, eventually altering their identities to a point at which they acquiesce to inequality. According to the integrated perspective on legitimacy that we propose, the influence of validity and validity beliefs on the propriety beliefs of individuals may result in adaptation. When individuals exposed to inequality within their system "adapt,” they adjust and update their beliefs about the legitimacy of inequality, especially when they perceive that many members of this system-particularly actors who have some form of authority, such as regulators, judges, experts, and the media (Bitektine and Haack, 2015)— endorse it. In this view, actual or perceived validity and the cognitive orientation that it fosters have a subtle yet powerful influence on attitudinal approval and behavioral consent (Stryker, 1994). In other words, the "facticity" of inequality-the representation and perception of inequality as a fact — affects the legitimacy of inequality. The greater is the confidence that individuals have in "how things are” and the more they have externalized and objectified a given 
social order, the bigger will be the impact of validity on perceptions of "how things ought to be” (i.e., on the propriety of the established social order; (Berger and Luckmann, 1967). This argument is in line with empirical evidence that experiencing pronounced inequality in terms of income has a positive effect on the perception that differences in income are legitimate (Trump, 2017) and with the finding that actual or perceived levels of inequality affect what is considered a legitimate level of inequality (Austen, 2002; Kelley and Zagorski, 2004).

More broadly, our conjecture is in line with the findings of previous research that individuals adjust their identities (e.g., Ibarra, 1999) and cognitive schemata (Wang and Morris, 2010) when new environmental stimuli generate perceptions that are inconsistent with the beliefs and worldviews they previously held (Fiske and Taylor, 2013). For instance, Lok (2010) found that as the concept of shareholder value gained ground, both corporate decision-makers and institutional investors adapted their identities to this increasingly dominant concept. Likewise, research on institutional logics (Thornton et al., 2012) has stressed that novice actors (i.e., actors with little experience of a certain logic) have to learn the "rules" of that logic in order to become socialized and to be able to act proficiently. Psychological research on attitudes also indicates that individuals develop their beliefs and worldviews through their interaction with the social world. For instance, according to the theory of social learning, people develop their beliefs about novel objects by observing others (Bandura, 1977)—an idea that bears striking similarity to sociological views of institutions (Berger and Luckmann, 1967; DiMaggio and Powell, 1991).

Drawing on these findings, we posit that people with little exposure to inequality adjust their propriety beliefs in line with what they perceive as the validity (i.e., the perceived inevitability, strength, and collective approval) of inequality.

Hypothesis 1: The process of adaptation facilitates the legitimation of inequality among the new members of a system of inequality over time. 
Furthermore, we assume that, within a given system, the speed with which individuals adapt their propriety beliefs to the perceived validity of inequality is contingent on these individuals’ previous exposure to a system of equality. We suggest that the longer individuals have lived in and experienced a system of equality, the slower will be their adaptation to a system of inequality. Our conjecture is corroborated by the theory of social judgment, which distinguishes between the stage of "judgment formation" and the stage of "judgment use" (Tost, 2011). In the stage of judgment formation, individuals consciously and unconsciously process and evaluate information they receive to form legitimacy judgments, which they then deploy in the stage of "judgment use.” Earlier studies indicate that the more frequently cognitive schemas are activated and confirmed, the stronger they become (e.g., Schützwohl, 1998). On that basis, we argue that the more often individuals use their legitimacy judgments, the stronger and more resilient their propriety beliefs become. As a consequence, the longer these individuals have lived in a system of equality, the weaker will be their propriety belief in the legitimacy of inequality.

We argue that a strong and firmly established belief in the legitimacy of equality can negatively affect the speed with which individuals adapt to a system of inequality — a point which is supported by research on social cognition as well as by the literature on system justification. First, there is ample evidence that individuals interpret new information in a way that supports their previously held beliefs and that they are more likely to ignore information that is inconsistent with these beliefs (Nickerson, 1998). Taber and Lodge (2006) have concluded that most people are "motivated skeptics” who actively seek to refute contrary arguments on issues that they support and feel competent to judge. Transferring these insights to our context, we suggest that individuals with strong propriety beliefs in the legitimacy of equality are less likely to reassess their unfavorable judgment about inequality, even when they become members of a system in which inequality is deemed legitimate, because they tend to ignore or argue against inconsistent information. 
Second, according to system justification theory, individuals tend to hold favorable propriety beliefs about the system in which they currently live and work. What motivates them to do so is the need to believe in a just world and to maintain a positive self-image (Jost et al., 2015). For the same reason, we expect that individuals are motivated to hold favorable propriety beliefs about the system in which they have lived in the past, particularly if that system is now devalued (e.g., by members of the new system; (Jost et al., 2004). We argue that the longer individuals have lived in a system of equality, the more likely they will be to hold favorable beliefs about this system and to believe that the new system lacks legitimacy.

However, it seems unlikely that individuals who have lived in a system of equality for a long time will reject a system of inequality indefinitely. Because perceptions of validity create a normative order that rests on the recognition of "how things are," the day-to-day experience of inequality and the very facticity of inequality will eventually re-orient the propriety beliefs of these individuals (Zelditch, 2001b). This conjecture is in line with evidence that individuals are more likely to judge as proper a legitimacy object that is valid (Walker et al., 1988). We expect that this likelihood is higher when individuals are exposed to validity cues for an extended period of time. Also, we suppose that, over time, individuals will identify less with the system in which they lived in the past and will identify more with the system in which they currently live and work. Consequently, we expect that individuals who have been exposed to a system of equality for a long time will gradually adapt to a system of inequality, even if they initially opposed that system. This leads us to the following hypothesis:

\section{Hypothesis 2: The longer the new members of a system of inequality have}

been exposed to a system of equality, the more slowly these members will adapt their propriety beliefs to the perceived validity of inequality.

\section{Replacement}

A second mechanism that may facilitate the legitimation of inequality among the new members of a system of inequality is that of replacement (Firebaugh, 1992; Ryder, 1965), 
which refers to the process through which younger cohorts gradually replace older cohorts within a social system. Research has shown that replacement processes often account for changes in values and beliefs within a social system, because the values and beliefs of the younger generation differ from those of the older generation, mainly as a result of their different socialization and experience. For instance, Tilcsik (2010) demonstrated that the budgeting system of a post-communist bureaucracy only changed after members of the "Old Guard" were replaced by "Reformists," a group of young technocrats who held favorable legitimacy beliefs about a new market-based budgeting system. The pivotal effect of cohort replacement is also illustrated by a study conducted by Rao, Monin, and Durand (2003, p. 808), which shows that the institutional change from classic to nouvelle cuisine was "accomplished gradually when a chef succeeded his father or father-in-law.” Given that "cohort differences may often matter more than life stage differences” (i.e., adaptation), King (2011) concluded that it is strange that past research has ignored cohort replacement as an important micro-level process of institutional change.

We expect that the process of replacement, particularly due to generational changes, facilitates the legitimation of a system of inequality. From an integrated legitimacy perspective, and on the grounds that led us to posit the previous hypothesis, we believe that people who have lived in a system of equality for a long time will adapt relatively slowly to a system of inequality. However, these people will be gradually replaced by a new generation of people who will be born into the system of inequality and thus will have no commitment to or personal interest in a system of equality. For this reason, we argue that the collective-level legitimacy of inequality will increase over time. In sum, the members of a system of inequality who have not adapted their propriety beliefs to the perceived validity of inequality will be gradually replaced by cohorts with more favorable propriety beliefs about inequality:

Hypothesis 3: The process of replacement facilitates the legitimation of inequality among the new members of a system of inequality over time. 


\section{METHODS}

\section{The German Reunification as a Research Context}

We tested our hypotheses in the context of the German reunification. The division of Germany began with its separation into French, British, U.S., and Soviet occupational zones after World War II. A series of political developments culminated in the formation of two German states in 1949: the FRG, which resulted from the merging of the French, British, and U.S. zones, and the GDR, which was established in the territory of the Soviet zone. The FRG became a democratic state and established a capitalist economy that was based largely on competition between economic actors and on the right to private property (Kornai, 2000). Conversely, the GDR became a socialist republic and established a socialist economy that emphasized centralized planning and state ownership of the means of production (Kornai, 2000).

In the 1980s, the GDR experienced growing consternation over deficiencies in production, infrastructure, and political freedom (Patton, 2011). By the end of the 1980s, increasing numbers of refugees regularly left East Germany for the West, while GDR citizens began organizing peaceful protests against the GDR government. As a result of these developments as well as of broader political developments—notably, glasnost and perestroika in the Soviet Union (Patton, 2011) — the GDR's political leadership allowed GDR citizens to cross the border formally, which led to the fall of the Berlin Wall in November 1989. Immediately thereafter, the GDR and the FRG began negotiations about their reunification. This process, which was formally concluded on October 3, 1990, included the complete integration of the GDR into the political and economic system of the FRG.

The context of the German reunification lends itself to a study of the legitimation of inequality for two reasons. First, capitalist systems and socialist systems differ markedly with regard to the validity of social and economic inequality (e.g., van der Toorn et al., 2010). Capitalist systems are built on the principle of equity, which states that individuals should be re- 
warded for demonstrating greater productivity by receiving more resources (e.g., a higher income); thus, it is fair to assume that a certain degree of inequality is widely regarded as acceptable in capitalist systems (Wu, 2009). Socialist systems, on the other hand, are built on the principle of equality, according to which individuals should receive similar portions of resources regardless of their individual productivity (e.g., a similar income); thus, it is fair to assume that inequality is widely regarded as invalid and inacceptable in socialist systems. These assumptions are supported by research demonstrating that beliefs about the legitimacy of income inequality differed between socialist countries in Eastern Europe and capitalist countries in 1987 and that the East European public "held strongly egalitarian norms up to the last days of Communism” (Kelley and Zagorski, 2004, p. 351).

The ideological differences between the GDR and the FRG are also mirrored in the actual differences in the level of inequality that characterized each society. Income inequality was much higher in the FRG than in the GDR; in 1990, the Gini coefficient was about 150 percent higher in the FRG than in the GDR (Hauser and Becker, 1997). Fritze concluded that before reunification, the majority of East Germans had, unlike the citizens of the FRG, "internalized socialist values including conceptions of social equality, equity, equal opportunity and solidarity. Everybody was equal and employed” (1995, p. 10, quoted in Noll, 1996); translation by the authors).

Second, although several countries (e.g., Russia, Poland) experienced a similar transition from socialism to capitalism, the German reunification offers a unique context because it resembles a natural experiment (e.g., Alesina and Fuchs-Schündeln, 2007) with clearly defined subpopulations and a clearly defined external event (i.e., the transition from a context of relative equality to a context of relative inequality). As a consequence, changes in beliefs about the legitimacy of inequality can be plausibly attributed to the external event (Dunning, 2012). In our research context, only the citizens of the GDR experienced a transition, whereas the citizens of the FRG were less affected by the reunification. The contrast between the 
treatment condition — the GDR — and the control condition — the FRG—-that arose naturally as a result of reunification allowed us to control for confounding effects at the state level (e.g., governmental changes and economic downturns) that might affect the legitimation of inequality after reunification.

\section{Data and Sample}

To test our hypotheses, we used secondary data from the German General Social Survey (GGSS), a biennial survey on the values and attitudes of the German population (GESIS Leibniz-Institut für Sozialwissenschaften, 2016). Trained interviewers conducted face-to-face interviews with about 3,000 Germans drawn from a random sample of the population (18 years and older).

We restricted our sample to native German citizens, excluding anyone who had immigrated to Germany. We also excluded respondents born in or after 1989, as these respondents would be too young to have experienced the transition from socialism to capitalism. We limited the analysis to eight waves of GGSS data (1991, 1994, 1998, 2000, 2004, 2008, 2010, and 2014), because some of our variables had not been included in all waves. After eliminating respondents with incomplete data, the final sample included 13,812 observations.

\section{Dependent Variable}

To measure beliefs about the legitimacy of inequality, we used three items from the scale by Mayer, Kraus and Schmidt (2014), which is included in multiple waves of the GGSS: (1) "Only when differences in income and in social standing are large enough is there an incentive for individual achievement”; (2) “Differences in status between people are acceptable because they basically reflect what people have made of the opportunities they have had”; and (3) “On the whole, I consider the social differences in our country just.” The items were measured on a four-point scale (1 = “Completely disagree”; 4 = "Completely agree”). The reliability of the scale was acceptable $(\alpha=0.67)$. 
To assess whether the items reflected a latent construct, we randomly split our sample into two groups and conducted exploratory factor analysis (EFA) for the first half of the sample and confirmatory factor analysis (CFA) for the second half. We included ten additional items from the GGSS (available upon request) that ascertain whether individuals think that upward social mobility is due to meritocratic principles (e.g., ability, intelligence) or ascriptive principles (e.g., social origin, networks) in the EFA (Noll and Roberts, 2003). A principal component factor analysis with varimax rotation indicated a three-factor solution and showed that the three items loaded (loading min $=|0.70|)$ on a single factor $($ Eigenvalue $=1.75)$. Also, the three items had low cross-loadings on the two other factors (loading max $\leq|0.15|$ ), and the additional items had low cross-loadings on our dependent variable (loading $\max _{\max } \leq|0.21|$ ). The CFA also indicated a good fit of the three-factor structure $\left(\chi^{2}=661.49 ; \mathrm{p}<0.001 ; \mathrm{df}=62\right.$; $\mathrm{CFI}=0.91 ; \mathrm{TLI}=0.88 ; \mathrm{SRMR}=0.049 ; \mathrm{RMSEA}=0.051)$. Chi-square difference tests suggested that the 3-factor model provided a better fit $(\mathrm{p}<0.001)$ than competing models (two 2factor models and a 1-factor model). In summary, the results showed that the three items reflect a single factor and that the construct is distinguishable from related constructs.

Finally, we tested the criterion-related validity of our construct. Previous studies (e.g., Finseraas, 2009) indicated a relationship between inequality and the demand for the redistribution of societal resources (e.g., income). We used two questions from the GGSS to capture the respondents' preferences for redistribution: "Should social benefits be cut in the future, should things stay as they are, or should social benefits be extended?” (1 = "should be cut”; 2 = "should stay as they are"; 3 = "should be extended") and "By and large, economic profits are nowadays distributed fairly in Germany” (1 = “completely disagree”; 4 = “completely agree”). We found that individuals’ beliefs in the legitimacy of inequality had a negative correlation with their preferences for extending social benefits $(r=-0.26 ; \mathrm{p}<0.001)$, and their beliefs about whether economic profits are distributed fairly $(r=0.36 ; p<0.001)$. These findings provide evidence for the construct's criterion-related validity. 


\section{Independent and Moderator Variables}

The primary independent variable in our study is whether the respondents had lived in the GDR prior to 1990, because only people who were born and lived in the GDR before reunification experienced the transition from an equality context (socialism) to an inequality context (capitalism). The GGSS conducted in 1991, 1994, 2000 and 2004 contain information about the respondents' place of birth. We created a dummy variable with a value of 1 if the respondent was born in the GDR and 0 if the respondent was born in the FRG. Because the GGSS conducted in 1998, 2008, 2010 and 2014 contained no information about the respondents’ place of birth, we used information about the place where respondents lived in their youth. This information is a valid indicator of a person's place of birth, because moving from the GDR to the FRG was almost impossible after the Berlin Wall was erected in 1961. We coded the dummy variable as 1 if the respondent had lived in the GDR during his or her youth and as 0 if the respondent had lived in the FRG.

To analyze the effects of the processes of adaptation (Hypothesis 1), we constructed a variable called years spent in Germany after 1990 that reflected the number of years a respondent had lived in reunified Germany after 1990 (for a similar approach, see Firebaugh, 1989). The variable can take values from 1 (the respondent was surveyed in 1991) to 24 (the respondent was surveyed in 2014).

To analyze the effects of cohort replacement (Hypothesis 3), we constructed a variable called years spent in the GDR/FRG prior to 1990 that reflected how long a respondent had lived in either half of the divided Germany up to reunification. Because the GGSS contains no question asking how many years a respondent spent in the GDR/FRG prior to 1990, we used an indirect measure. Given that emigration from East Germany to West Germany was very difficult, we measured the years a respondent had spent in the GDR/FRG between the year 1945, when Germany was split into occupational zones, and 1990, when the two German 
states were reunited. To do so, we calculated the difference between a respondent's year of birth and the year 1990. This variable can take values from 1 to 45 .

\section{Control Variables}

We included several variables to rule out alternative explanations. First, we controlled for the respondents’ income, because this variable affects system justification (Jost et al., 2003c). We measured the variable by using the natural logarithm of the monthly net family income. Second, we included the respondents' self-assessed current financial situation to control for differences in wealth. The financial situation was measured on a five-point scale $(1=$ very bad; 5 = very good). Third, we created a dummy variable that captured whether the respondents were unemployed $(1=$ yes $)$ at the time of the interview, which might affect their belief in the legitimacy of inequality. Fourth, we controlled for the respondents' level of education, because less educated persons are more likely to perceive social inequalities as just (Jost et al., 2003c). We constructed dummy variables for low levels of education (1 = yes) and medium levels of education ( 1 = yes). A low level of education meant that the respondents had either no school certificate or only a "basic" secondary school certificate (from a secondary school known in Germany as a "Hauptschule”), while a medium level meant that the respondents had graduated from "intermediate” high school (i.e., from the "Realschule”). Respondents with a university-entrance certificate (i.e., “Abitur”) or an academic degree were considered to have a high level of education, which was the reference category. Fifth, because liberals and conservatives tend to hold different beliefs about the legitimacy of inequality (Jost et al., 2003b), we controlled for the respondents' political view, which was measured on a tenpoint scale $(1$ = left-wing; 10 = right-wing). Sixth, we controlled for key demographic variables by including a dummy variable to control for gender ( 0 = male; $1=$ female $)$ and a variable to control for age. Finally, we included dummy variables for each wave of the GGSS to control for year fixed-effects. 


\section{Statistical Analyses}

The GGSS does not represent a panel; in other words, it does not provide repeated observations for all respondents. Rather, it uses a cross-sectional repeated measures design, which means that a random sample of the German population is surveyed in different years. Repeated cross sections are comparable to panel data, provided that two conditions are met. First, the dependent variable must be unrelated to population replacement within a cohort (Firebaugh, 1992). That is, the death rates of individuals from the same cohort exhibiting high and low levels of the dependent variable should be the same. This condition is likely to be fulfilled in our study, because we have no evidence that the propriety beliefs of East Germans are correlated with mortality. Second, the size of each sample should exceed a threshold (e.g., 200 observations, see Verbeek and Nijman, 1992) to reduce bias in the population mean. Because the sample size in our study exceeds 1,500 observations in each wave, we expect no bias in the population mean. Following previous studies (e.g., Alesina and Fuchs-Schündeln, 2007), we analyzed our data using OLS with robust standard errors. We conducted all analyses using Stata 14.

An important difference between this study and previous studies on social change (e.g., Cotter et al., 2011) is that, while previous studies aimed to explain absolute changes in people's attitudes, we focus on relative changes - that is, on how the differences between the beliefs of our control group (West Germans) and our treatment group (East Germans) about the legitimacy of inequality changed over time. As we explained earlier, because both groups live in reunified Germany, they are similarly affected by external events (e.g., economic conditions) that can influence an individual's belief in the legitimacy of inequality. Thus, changes in the differences between the beliefs that each group holds about the legitimacy of inequality are likely to have been caused by the mechanisms we have described and not by unobserved external events (Alesina and Fuchs-Schündeln, 2007). 


\section{RESULTS}

Table I summarizes the descriptive statistics. We detected a high correlation between age and the number of years spent in the GDR or FRG prior to $1990(\mathrm{r}=0.85 ; \mathrm{p}<0.001)$, and variance inflation factors (VIFs) indicated potential problems of multicollinearity $\left(\mathrm{VIF}_{\text {age }}=\right.$ 8.61). To check whether multicollinearity affected our results, we ran all regressions again, excluding age. The results were completely identical, indicating that our models are not affected by multicollinearity. This allowed us to include age as a control variable. We meancentered all continuous variables to improve interpretation.

Insert Table I about here

Before testing the hypotheses, we explored how the beliefs that the former citizens of the GDR and the FRG held about the legitimacy of inequality developed over time. Figure 1 shows that these differences between former GDR citizens and former FRG citizens increased between 1991 and 1998; between 2000 and 2014, however, they decreased. One remarkable finding is that in 1991—barely one year after reunification — the differences in beliefs about the legitimacy of inequality between former GDR citizens and former FRG citizens were rather low. Indeed, on the basis of our theory, we expected that former GDR citizens would initially feel that inequality lacks legitimacy, because equality was an important principle of the socialist system. We will explore this finding in more detail in the next section. Because the very low difference in propriety beliefs between former GDR citizens and former FRG citizens is likely to be an outlier, we included in the regression the interaction term "lived in the GDR prior to 1990 x year 1991” to control for this interesting finding.

Insert Figure 1 and Table II about here

Hypothesis 1 posits that the legitimacy of inequality increases among the new members of a system of inequality over time, because they adapt their propriety beliefs to the perceived 
validity of inequality. To test the hypothesis, we included in the regression the interaction term “lived in the GDR prior to 1990 x years spent in Germany after 1990” (see Table II, Model 2). This interaction term is positive and significant $(b=0.018 ; p<0.001)$, supporting Hypothesis 1. As Figure 2 shows, the differences in the beliefs that former GDR citizens and former FRG citizens held about the legitimacy of inequality shrank over time. A simple slope analysis (Dawson, 2014) indicates that the difference between East Germans and West Germans is significant at each value of the moderator $(p<0.05)$ but shrinks over time ( about 0.50 in 1991 vs. about 0.10 in 2014). This result indicates that a process of adaptation took place. Furthermore, Figure 2 shows that the change in the differences between former citizens of the GDR and FRG over time is mainly due to increases in propriety beliefs among former citizens of the GDR.

Hypothesis 2 states that the longer new members of a system of inequality have been exposed to a system of equality, the slower will be their adaptation to the system of inequality. To test this hypothesis, we included a three-way interaction term in the regression (see Table II, Model 3): “lived in the GDR prior to 1990 x years spent in Germany after $1990 \mathrm{x}$ years spent in the GDR/FRG prior to 1990.” The results support Hypothesis 2: the coefficient of the interaction term was negative and significant $(b=-0.0002 ; \mathrm{p}=0.044)$. To better interpret the result, we plotted the interaction for three groups: individuals who spent 15, or 30, or 45 years, respectively, in the GDR or the FRG prior to 1990. As Figure 3 indicates, the new members of a system of inequality who were previously exposed to a system of equality for 45 years take the longest to adapt to the new system, whereas the new members of a system of inequality who were previously exposed to a system of equality for 15 years are the fastest to adapt to the new system.

Insert Figures 2, 3, and 4 about here 
Hypothesis 3 posits that the replacement of older actors with new actors in a system of inequality increases the legitimation of inequality among the members of this system. To test this hypothesis, we included the interaction term "lived in the GDR prior to $1990 \mathrm{x}$ years spent in the GDR/FRG prior to 1990” in the regression. The results (Table II, Model 2) support the hypothesis; the interaction term is negative and significant $(b=-0.007 ; \mathrm{p}<0.001)$. As Figure 4 shows, inequality is generally perceived as more legitimate among people who were socialized in the GDR for a relatively short time than among people who had spent a greater part of their lives in the GDR; however, we did not observe similar differences between people who were socialized for a relatively short time or relatively long time in the FRG. As the number of citizens who were not socialized in the former GDR increases, the population average of the years spent in the former GDR decreases (e.g., it dropped from 36.13 in 1994 to 27.26 in 2014). The slope analysis further indicates that the difference between East Germans and West Germans is statistically significant at each value of the moderator $(p<0.05)$ but is more pronounced among East Germans who had spent more years in the former GDR (about 0.38 after 45 years in the GDR; about 0.07 after 1 year in the GDR). This finding shows that, over time, replacement processes among former citizens of the GDR reduced the gap in beliefs about the legitimacy of inequality between the former citizens of the GDR and of the FRG.

We also analyzed the relative contribution of processes of adaptation and replacement to this convergence of perceptions using the method of linear decomposition (Firebaugh, 1989). The calculation shows that the relative contribution of adaptation is about four times higher than the contribution of replacement (calculation details are available upon request).

\section{Additional Analyses and Robustness Checks}

We conducted several analyses to check the robustness of our findings and to provide additional insights. First, we ran additional analyses to explore why differences in propriety beliefs of former GDR and former FRG citizens were initially relatively small and then in- 
creased after 1991 (see Figure 1). We considered two explanations for this pattern. On the one hand, East Germans may have expected that their own economic situation would improve in the near future and therefore considered inequality to be relatively legitimate. On the other hand, this pattern may reflect a more general dissatisfaction with socialism among East Germans, making the capitalist system more attractive to them by comparison. We used two questions from the GGSS to examine whether these conjectures could explain the pattern: (1) "What will your own financial situation be like in one year?” (1 = "considerably worse than today”; 5 = “considerably better than today”); and (2) "Socialism is basically a good idea; it was just put into practice badly” (1 = “strongly disagree”; 4 = “strongly agree”). We used OLS to test for differences in the attitudes of former GDR citizens between the years 1991 and 1994. The results showed that East Germans had higher expectations regarding their future economic situation in 1991 than in $1994(\mathrm{~b}=0.21$; $\mathrm{p}<0.001)$; however, we found no significant differences with regard to attitudes towards socialism $(b=-0.06 ; p=0.28)$. Therefore, we argue that initial euphoria among East Germans after reunification may explain the existence of only a small difference in the beliefs of East and West Germans about the legitimacy of inequality in 1991.

Second, studies have indicated that West and East Germany were very similar before 1945 (Alesina and Fuchs-Schündeln, 2007); however, it is possible that the observed differences in beliefs about the legitimacy of inequality may result from unobserved differences in attitudes and beliefs that existed before Germany was divided into two states. To test this alternative explanation, we checked whether the differences in the propriety beliefs of respondents who lived in adjacent regions_-namely, East and West Berlin-were similar to the differences in propriety beliefs between respondents who lived in East and West Germany in 1991. If the observed differences in propriety beliefs are the result of unobserved differences that existed before Germany was divided, then the differences between the inhabitants of East and West Berlin should be smaller, because Germans living in different parts of Berlin were 
unlikely to have had dissimilar beliefs before 1945. We found no significant difference in the coefficients of the variable lived in the GDR prior to 1990 between the two groups $\left(\chi^{2}=1.42\right.$; $\mathrm{p}=0.23$ ), which indicates that in 1991, the difference in propriety beliefs between the inhabitants of East and West Berlin was similar to the difference in propriety beliefs between the former citizens of the GDR and of the FRG. Thus, the observed differences in propriety beliefs are unlikely to have resulted from differences in those beliefs that are associated with the eastern and the western regions of Germany prior to 1945.

Third, we explored whether East and West Germans who were born after reunification also differ in their propriety beliefs. If the differences we observed in our analyses are indeed the result of being socialized in different systems, there should be no differences between East and West Germans who were raised in reunified Germany. The OLS shows no difference in propriety beliefs between East and West Germans born in or after $1989(\mathrm{~b}=-0.00 ; \mathrm{p}=0.997)$. This finding further increases our confidence that the differences we observed between East and West Germans result from being socialized in socialist and capitalist systems, respectively.

\section{DISCUSSION}

The aim of this paper was to develop and test a novel theory on how economic and social inequality becomes legitimized among the members of a social system. To build and test our theory, we blended system justification theory with the theory of social judgment and then proceeded to explore the legitimation of inequality in the unique setting of a natural experiment - the German reunification. From the perspective on legitimacy that we propose, we were able to identify two mechanisms through which inequality becomes legitimate. First, because the (perceived) validity of inequality influences the propriety beliefs about inequality that people form and hold, individuals exposed to inequality within a system adjust and update their beliefs about the legitimacy of inequality. Second, the legitimation of inequality is driven by cohort replacement; however, this effect is weaker than the first. Overall, this study 
offers important insights into the legitimation of inequality. In this section, we discuss the broader implications of our theorizing, the limitations of our approach, and the possibilities for future research.

\section{Theoretical Implications}

As a persistent characteristic of both Western and Eastern societies, inequality has attracted the attention of both policy-makers and researchers. For instance, former U.S. President Barack Obama (2016) identified inequality as one of the four future challenges for the United States, while the Pew Research Center (2014) found that people all over the world consider inequality to be a major problem. Piketty’s Capital in the Twenty-First Century (2014) has arguably become one of the most influential contemporary books in economics. Although this seems to be "a golden age for studying inequality” (The Economist, 2016), surprisingly little is known about why inequalities persist and why people, even those who are disadvantaged by inequality, tacitly approve of it (Costa-Lopes et al., 2013). A first important insight of our study is that the legitimation of inequality is influenced by its perceived validity. By blending system justification theory and the theory of social judgment, we clarified that what individuals experience as inevitable, enduring, and collectively approved has a subtle but powerful impact on their propriety beliefs. We also showed that the process through which people adapt their propriety beliefs is complemented by a process of replacement, through which older cohorts are substituted by younger cohorts with more favorable beliefs about the legitimacy of inequality. Our empirical analysis shows that the influence of adaptation is far stronger than the influence of replacement on legitimacy beliefs. Consequently, our findings indicate that the absence of public resentment toward inequality can be largely attributed to institutionalized legitimacy beliefs that underpin and perpetuate social and economic inequality.

This study's second contribution is that it provides insights into the subjective nature of legitimacy. Acknowledging that individuals are often active enactors of legitimacy, 
Deephouse and Suchman (2008) called on researchers to focus on how and where legitimacy is constructed. Indeed, legitimacy as a "generalized perception" (Suchman, 1995, p. 574) reflects the degree to which a particular legitimacy object gains collective approval. Collective approval is a subjectively created social construct that derives from the coalescence of individual perceptions that ultimately develop in the eye of the beholder; that is, in the psyche of individuals (Zimmerman and Zeitz, 2002). However, in recent organization and management research, hardly any studies have analyzed legitimacy empirically as a dependent variable (Deephouse and Suchman, 2008). Indeed, little is known about how individuals construe legitimacy and how different beholders within a specific stakeholder group assess the propriety of organizations, practices, and other types of legitimacy objects (Tost, 2011). Previous studies on legitimacy described human action in terms of stimulus and response, overlooking the fact that "individuals actively participate in perceiving, interpreting, and making sense of their world” (Scott, 2008, p. 37). This approach implies that individuals either hold no prior propriety beliefs or that prior propriety beliefs do not affect the formation of new legitimacy beliefs (Tost, 2011). Drawing on recent conceptual contributions to the social judgment perspective on legitimacy (Bitektine, 2011; Bitektine and Haack, 2015; Tost, 2011), our study indicates that previously held propriety beliefs influence the formation of new beliefs. Our research thus explains why different stakeholder groups (Lamin and Zaheer, 2012) and different individuals within these groups (Lange and Washburn, 2012; Voronov and Vince, 2012) may judge a legitimacy object very differently. In light of our findings, we recommend that future studies extend the current multi-level models of legitimacy to include a "historical" dimension acknowledging that "legitimacy is dependent on a history of events” (Suchman, 1995, p. 574). These extended models should take into account that individuals "own” a history that they “carry” with them and that may affect their present and future legitimacy judgments, as well as the actions that follow from such judgments (e.g., Lawrence et al., 2011). 
Our study also contributes to the development of a microfoundational research agenda in institutional theory. Although several scholars have encouraged research into the microfoundations of institutions (e.g., Cornelissen et al., 2015; Powell and Colyvas, 2008; Thornton et al., 2012) and inequality (e.g., Amis et al., 2017), few have responded to this call. Suddaby (2010) has criticized the disproportionate emphasis that scholars have placed on the structural aspects of institutions, such as isomorphism and decoupling, at the expense of their perceptual components and of the ideational processes that create meaning and legitimacy for organizational events and practices. Our study highlights that research on the microfoundations of institutions should not be limited to the micro level, on which psychology and behavioral economics focus. On the contrary, researchers should seek to explain how phenomena at the micro level are linked to higher-level structures and outcomes (Bitektine and Haack, 2015). Our integrative theory examines legitimacy at multiple interacting levels, viewing validity as a collective-level component of legitimacy and propriety and validity beliefs as individual-level components of legitimacy. We have also focused on theorizing and testing two important mechanisms, which we believe make legitimacy theory more supple and accurate but at the same time also more general (Stinchcombe, 1991). This study thus offers a rich opportunity for further research into the inter-subjective processes of perception, interpretation, interaction and meaning construction, which lie at the core of understanding institutional change and processes of legitimation and institutionalization (Suddaby, 2010).

Given that evaluators decide whether or not to support a practice depending on whether they believe that practice to be legitimate (Hoefer and Green, 2016; Huy et al., 2014; Tost, 2011), our insights also have important implications for the study of management and organizations in general, and particularly for research on organizational justice (e.g., Colquitt et al., 2013; Greenberg and Colquitt, 2005) and the consequences of inequality in organizations (e.g., Bloom and Michel, 2002; Sieweke et al., 2016). For instance, previous research has shown that employee reactions to different forms of inequality (e.g., pay inequality, gender 
inequality) depend on the extent to which such inequalities are perceived to be fair (e.g., Shore et al., 2006). Our study adds two novel concepts to this conversation that allow us to gain a better understanding of employees' fairness perceptions and resulting reactions. First, employees' propriety beliefs about the legitimacy of inequality can influence their fairness perceptions, thus indirectly affecting how they react to inequality. For instance, employees who deem inequality to be proper may also perceive it to be fair and thus react less negatively to it. Second, the validity of inequality within a team or an organization may further influence the perceived fairness of inequality, above and beyond the effect of propriety beliefs. In other words, employees who work in an organizational context in which they perceive that others perceive inequality to be appropriate will tend to react less negatively to inequality compared to those who work in a setting in which inequality is contested. Also, our findings suggest that employees who are embedded in a context in which a specific type of inequality is regarded as valid will adapt their propriety beliefs over time, meaning that their perception of the fairness of that type of inequality is likely to increase the longer they work in that context. Indeed, according to our integrative theory, we may even expect that employees who are embedded in a context with high levels of inequality will tend to perceive inequality as fairer over time, as they increasingly perceive inequality as a social fact.

\section{Practical Implications}

Our research provides evidence that individuals react to actual or perceived inequality by adapting their legitimacy beliefs to the level of inequality that they experience. The implication of this finding is disturbing, as it suggests that informing and educating the public about growing levels of inequality may not necessarily promote resistance to this trend; in fact, it actually may have the counter-intuitive effect of legitimizing inequality (Trump, 2017). Nevertheless, policy-makers can help to delegitimize inequality and thus contribute to social justice and positive social change. From our integrated theory of inequality legitimation, it follows that the actual or perceived validity of equality (as the opposite of inequality) needs to 
be strengthened. If equality is perceived as valid and collectively approved, then individuals will be more willing to endorse measures that promote equality and to assess inequality as improper.

There are several ways of promoting such perceptions and, as a consequence, change in legitimacy beliefs about inequality. First, policy-makers can activate validity cues by stressing that a significant or growing number of actors work against the status quo. For instance, in the context of gender inequality, the British government found that when the same statistic was presented to companies positively (i.e., 94 percent of companies had at least one woman on their board) rather than negatively (i.e., only 17 percent of board members were women), these companies improved their promotion policies for women (Bohnet, 2016). Second, research has shown that individuals are more willing to embrace change when it is perceived as natural (Suddaby and Greenwood, 2005) and inevitable or extremely likely to occur (Jost et al., 2015). Third, reference to tradition or to the longevity of a system leads to higher scores on system justification in surveys (Blanchar and Eidelman, 2013). By corollary, reducing the perceived longevity of a system of inequality and augmenting the perception that changing that system is consistent with established "scripts" may enhance the perception that a system can be changed and induce in people the motive to generate such change (Johnson and Fujita, 2012).

Amplifying the perception that practices leading to system change are becoming more widespread and persistent and that change is inevitable signals to evaluators that these practices are valid and thus offers an important strategy for delegitimizing systems of inequality and bringing about institutional change. As Kay and Zanna (2009) explained, changing perceptions of the social context through actual changes to social reality (e.g., by introducing equality policies), changes in the perception of social reality (e.g., by launching media campaigns that portray a considerable decline in inequality), or even changes in the perception of 
where social reality is inevitably heading may represent a necessary (albeit insufficient) condition for fostering support of a more equal status quo.

\section{Limitations and Future Research}

An unanticipated finding was that in 1991, the citizens of the former GDR and the FRG apparently held quite similar beliefs about the legitimacy of inequality. This finding was unexpected because our theory suggested that after reunification, there would be pronounced differences in the propriety beliefs of former GDR and FRG citizens about inequality. One possible explanation for this finding is that GDR citizens resented the system in which they lived and desired the political liberties and material privileges that FRG citizens enjoyed. If GDR citizens not only resented the system but also felt that it lacked legitimacy, this may have affected their legitimacy beliefs about the system's properties, including the principle of equality.

We were also surprised to find that after 1991, the legitimacy beliefs of West Germany and East Germans diverged, whereas they started to converge after 1998 (see Figure 1). East Germans, as we found, expected their economic situation to improve in the reunified capitalist Germany. Research on legitimacy as a social judgment indicates that optimism and other types of positive affect can influence legitimacy judgments and can also induce positive legitimacy spillovers to entities affiliated with a focal legitimacy object (Haack et al., 2014). As a result of a positive spillover, positive emotions such as hope, gratitude, and euphoria, which East Germans generally experienced right after reunification, may have contributed to the legitimation of the capitalist system and its properties among East Germans, including inequality. However, considering the divergence of legitimacy beliefs about inequality among former GDR and former FRG citizens after 1991, beliefs about the legitimacy of inequality among former GDR citizens apparently lacked strength and stability. It seems plausible to assume that many East Germans experienced disillusionment, disappointment, and shame when they were hit by economic hardship (e.g., the unemployment rate in the former territory of the 
GDR grew to about 16 percent in 1994, see Flockton, 1998). In turn, and in line with the conjecture that legitimacy is based on emotional experience (e.g., Haack et al., 2014), negative affect may have reduced the approval rates of capitalism and its characteristics, including inequality, among former GDR citizens.

Unfortunately, our study is limited by the lack of information on legitimacy beliefs before reunification. This limitation makes it difficult to ascertain which explanation applies to our context. Anecdotal evidence suggests that legitimacy judgments about inequality in the former GDR were far from uniform, and the fact that none of the surveys on which we draw were taken before the fall of the Berlin Wall makes it rather difficult to assess reliably the respondents' beliefs about inequality before 1989. Thus, there is a need for research into the legitimacy beliefs of East Germans about the GDR's political system and its properties before reunification. Further research might explore behavioral measures of legitimacy beliefs about the socialist system. One such measure might involve assessing activities that signal protest against the system, such as vandalism (e.g., graffiti) and various forms of cultural resistance that indicate non-conformity (e.g., tattoos or the distribution of politically critical pop songs).

Further research should be undertaken to develop a more fine-grained understanding of legitimacy in the sense of acceptability and tacit approval (i.e., "weak validation”) versus legitimacy grounded in active and extensive support and endorsement (i.e., “strong validation”). Specifically, we consider it important to theorize the threshold levels at which controversial legitimacy objects (e.g., organizations or practices) shift from being considered acceptable to being considered unacceptable. Related to our examination, how low would the ratings for inequality have to go to be considered not tacit approval but rather disapproval, with the prospect of inciting resistance and thus social change (Tost, 2011)? With respect to institutionalization, how pervasive does such a low rating needs to be in order to cause inequality to be considered unacceptable? Suddaby and colleagues (2017) posited that, in extreme cases, legitimacy objects can remain valid even though not a single evaluator privately endorses the ob- 
ject (i.e., propriety is zero) or even though all evaluators privately oppose the object (i.e., propriety is negative). In this view, very low and even negative ratings among a majority of evaluators may not preclude the acceptability and stability of systems of inequality and other forms of social dominance.

As we discussed earlier, the mechanisms that we found to contribute to the legitimation of inequality may also be used to delegitimize inequality. For instance, if the new members of a system do not view inequality as legitimate, replacement may delegitimize rather than legitimize inequality. In other words, while we identified adaptation and replacement as two major mechanisms of inequality legitimation, the same mechanisms may work in the opposite direction in other contexts. This suggests that our theory may relate generally to changes in the status quo rather than to changes associated specifically with inequality. In sum, there is abundant room for specifying and further testing the boundaries of our integrative theory. 


\section{NOTES}

'Propriety beliefs are the content of "propriety judgments" (Hoefer and Green, 2016). In this paper, we draw on the more basic belief concept, because our propriety measure captures beliefs, not judgments (see the methods section below). 


\section{REFERENCES}

Alesina, A., Di Tella, R. and MacCulloch, R. (2004). 'Inequality and happiness: Are Europeans and Americans different?'. Journal of Public Economics, 88, 2009-42.

Alesina, A. and Fuchs-Schündeln, N. (2007). 'Good-bye Lenin (or not?): The effect of communism on people's preferences'. American Economic Review, 97, 1507-28.

Amis, J., Munir, K. and Mair, J. (2017). 'Institutions and economic inequality'. In Greenwood, R., Oliver, C., Lawrence, T. B. and Meyer, R. (Eds.), The Sage handbook of organizational institutionalism. Thousand Oaks: Sage.

Ashforth, B. E. and Gibbs, B. W. (1990). 'The double-edge of organizational legitimation'. Organization Science, 1, 177-94.

Austen, S. (2002). 'An international comparison of attitudes to inequality'. International Journal of Social Economics, 29, 218-37.

Bandura, A. (1977). Social learning theory. New York: General Learning Press.

Berger, P. L. and Luckmann, T. (1967). The social construction of reality - A treatise in the sociology of knowledge. New York: Anchor Books.

Bitektine, A. (2011). 'Toward a theory of social judgments of organizations: The case of legitimacy, reputation, and status'. Academy of Management Review, 36, 151-79.

Bitektine, A. and Haack, P. (2015). 'The macro and the micro of legitimacy: Towards a multilevel theory of the legitimacy process'. Academy of Management Review, 40, 49-75.

Blanchar, J. C. and Eidelman, S. (2013). 'Perceived system longevity increases system justification and the legitimacy of inequality'. European Journal of Social Psychology, 43, 238-45.

Bloom, M. and Michel, J. G. (2002). 'The relationships among organizational context, pay dispersion, and managerial turnover'. Academy of Management Journal, 45, 33-42.

Bohnet, I. (2016). What works: Gender equality by design. Harvard: Harvard University Press.

Colquitt, J. A., Scott, B. A., Rodell, J. B., Long, D. M., Zapata, C. P., Conlon, D. E.et al. (2013). 'Justice at the millennium, a decade later: A meta-analytic test of social exchange and affect-based perspectives'. Journal of Applied Psychology, 98, 199-236.

Cornelissen, J. P., Durand, R., Fiss, P. C., Lammers, J. C. and Vaara, E. (2015). 'Putting communication front and center in institutional theory and analysis'. Academy of Management Review, 40, 10-27.

Costa-Lopes, R., Dovidio, J. F., Pereira, C. R. and Jost, J. T. (2013). 'Social psychological perspectives on the legitimation of social inequality: Past, present and future'. European Journal of Social Psychology, 43, 229-37.

Cotter, D., Hermsen, J. M. and Vanneman, R. (2011). 'The end of the gender revolution? Gender role attitudes from 1977 to 2008'. American Journal of Sociology, 117, 25989.

Dawson, J. F. (2014). 'Moderation in management research: What, why, when, and how'. Journal of Business and Psychology, 29, 1-19.

Deephouse, D. L., Bundy, J., Tost, L. P. and Suchman, M. (2017). 'Organizational legitimacy: Six key questions'. In Greenwood, R., Oliver, C., Lawrence, T. B. and Meyer, R. (Eds.), The Sage handbook of organizational institutionalism (2nd edition). Thousand Oaks: Sage, 27-54.

Deephouse, D. L. and Suchman, M. (2008). 'Legitimacy in organizational institutionalism'. In Greenwood, R., Oliver, C., Suddaby, R. and Sahlin, K. (Eds.), The Sage handbook of organizational institutionalism. Thousand Oaks: Sage, 49-77.

Della-Fave, L. R. (1986). 'Toward an explication of the legitimation process'. Social Forces, 65, 476-500. 
DiMaggio, P. J. and Powell, W. W. (1991). 'Introduction'. In Powell, W. W. and DiMaggio, P. J. (Eds.), The new institutionalism in organizational analysis. Chicago: University of Chicago Press, 1-38.

Dunning, T. (2012). Natural experiments in the social sciences. Cambridge: Cambridge University Press.

Felin, T., Foss, N. J. and Ployhart, R. E. (2015). 'The microfoundations movement in strategy and organization theory'. Academy of Management Annals, 9, 575-632.

Finseraas, H. (2009). 'Income inequality and demand for redistribution: a multilevel analysis of European public opinion'. Scandinavian Political Studies, 32, 94-119.

Firebaugh, G. (1989). 'Methods for estimating cohort replacement effects'. Sociological Methodology, 19, 243-62.

Firebaugh, G. (1992). 'Where does social-change come from? Estimating the relative contributions of individual change and population turnover'. Population Research and Policy Review, 11, 1-20.

Fiske, S. and Taylor, S. (2013). Social cognition: From brains to culture. London: Sage.

Flockton, C. (1998). 'The German economy since 1989/90: Problems and prospects'. In Larres, K. (Ed.), Germany since unification: The domestic and external consequences. London: Macmillan, 63-87.

GESIS - Leibniz-Institut für Sozialwissenschaften. (2016). Allgemeine Bevölkerungsumfrage der Sozialwissenschaften ALLBUS - Kumulation 1980-2014. Köln: GESIS Datenarchiv.

Greenberg, J. (2010). 'Organizational injustice as an occupational health risk'. Academy of Management Annals, 4, 205-43.

Greenberg, J. and Colquitt, J. A. (Eds.). (2005). Hanbook of organizational justice. New Jersey: Lawrence Erlbaum.

Haack, P., Pfarrer, M. and Scherer, A. G. (2014). 'Legitimacy-as-feeling: How affect leads to vertical legitimacy spillovers in transnational governance'. Journal of Management Studies, 51, 634-66.

Halter, D., Oechslin, M. and Zweimuller, J. (2014). 'Inequality and growth: The neglected time dimension'. Journal of Economic Growth, 19, 81-104.

Hauser, R. and Becker, I. (1997). 'The development of income distribution in the Federal Republic of Germany during the 1970s and 1980s'. In Gottschalk, P., Gustafsson, B. A. and Palmer, E. E. (Eds.), Changing Patterns in the Distribution of Economic Welfare. Cambridge: Cambridge University PRess, 184-219.

Hoefer, R. L. and Green, S. E. (2016). 'A rhetorical model of institutional decision making: The role of rhetoric in the formation and change of legitimacy judgments'. Academy of Management Review, 41, 130-50.

Huy, Q. N., Corley, K. G. and Kraatz, M. S. (2014). 'From support to mutiny: Shifting legitimacy judgments and emotional reactions impacting the implementation of radical change'. Academy of Management Journal, 57, 1650-80.

Ibarra, H. (1999). 'Provisional selves: Experimenting with image and identity in professional adaptation'. Administrative Science Quarterly, 44, 764-91.

Johnson, C. (2004). 'Introduction: Legtimacy processes in organizations'. Research in the Sociology of Organizations, 22, 1-24.

Johnson, C., Dowd, T. J. and Ridgeway, C. L. (2006). 'Legitimacy as a social process'. Annual Review of Sociology, 32, 53-78.

Johnson, I. R. and Fujita, K. (2012). 'Change we can believe in: Using perceptions of changeability to promote system-change motives over system-justification motives in information search'. Psychological Science, 23, 133-40.

Jost, J. T. and Banaji, M. R. (1994). 'The role of stereotyping in system-justification and the production of false consciousness'. British Journal of Social Psychology, 33, 1-27. 
Jost, J. T., Banaji, M. R. and Nosek, B. A. (2004). 'A decade of system justification theory: Accumulated evidence of conscious and unconscious bolstering of the status quo'. Political Psychology, 25, 881-919.

Jost, J. T., Blount, S., Pfeffer, J. and Hunyady, G. (2003a). 'Fair market ideology: Its cognitive-motivational underpinnings'. Research in Organizational Behavior, 25, 5391.

Jost, J. T., Gaucher, D. and Stern, C. (2015). "'The world isn't fair" - A system justification perspective on social stratification and inequality'. In Mikulincer, M. and Shaver, P. R. (Eds.), APA handbook of personality and social psychology. Washington: American Psychological Association, Vol. 2, 317-40.

Jost, J. T., Glaser, J., Kruglanski, A. W. and Sulloway, F. J. (2003b). 'Political conservatism as motivated social cognition'. Psychological Bulletin, 129, 339-75.

Jost, J. T. and Hunyady, O. (2005). 'Antecedents and consequences of system-justifying ideologies'. Current Directions in Psychological Science, 14, 260-65.

Jost, J. T. and Major, B. (2001). The psychology of legitimacy: Emerging perspectives on ideology, justice, and intergroup relations. New York: Cambridge University Press.

Jost, J. T., Pelham, B. W., Sheldon, O. and Ni Sullivan, B. (2003c). 'Social inequality and the reduction of ideological dissonance on behalf of the system: Evidence of enhanced system justification among the disadvantaged'. European Journal of Social Psychology, 33, 13-36.

Kay, A. C., Czaplinski, S. and Jost, J. T. (2009a). 'Left-right ideological differences in system justification following exposure to complementary versus noncomplementary stereotype exemplars'. European Journal of Social Psychology, 39, 290-98.

Kay, A. C. and Friesen, J. (2011). 'On social stability and social change: Understanding when system justification does and does not occur'. Current Directions in Psychological Science, 20, 360-64.

Kay, A. C., Gaucher, D., Peach, J. M., Laurin, K., Friesen, J., Zanna, M. P.et al. (2009b). 'Inequality, discrimination, and the power of the status quo: Direct evidence for a motivation to see the way things are as the way they should be'. Journal of Personality and Social Psychology, 97, 421-34.

Kelley, J. and Zagorski, K. (2004). 'Economic change and the legitimation of inequality: The transition from socialism to the free market in Central-East Europe'. Research in Social Stratification and Mobility, 22, 319-64.

King, B. (2011). Cohort replacement and institutional change. Available at: https://orgtheory.wordpress.com/2011/10/25/cohort-replacement-and-institutionalchange/ [accessed 6 April 2016].

Kornai, J. (2000). 'What the change of system from socialism to capitalism does and does not mean'. Journal of Economic Perspectives, 14, 27-42.

Lamin, A. and Zaheer, S. (2012). 'Wall Street vs. Main Street: Firm strategies for defending legitimacy and their impact on different stakeholders'. Organization Science, 23, 4766.

Lange, D. and Washburn, N. T. (2012). 'Understanding attributions of corporate social irresponsibility'. Academy of Management Review, 37, 300-26.

Laurin, K., Gaucher, D. and Kay, A. (2013). 'Stability and the justification of social inequality'. European Journal of Social Psychology, 43, 246-54.

Lawrence, T. B., Suddaby, R. and Leca, B. (2011). 'Institutional work: Refocusing institutional studies of organizations'. Journal of Management Inquiry, 20, 52-58.

Lok, J. (2010). 'Institutional logics as identity projects'. Academy of Management Journal, 53, 1305-35.

Luttig, M. (2013). 'The structure of inequality and Americans' attitudes toward redistribution'. Public opinion quarterly, 77, 811-21. 
Mayer, K. U., Kraus, V. and Schmidt, P. (2014). Sozial Ungleichheit. [Social inequality]: Zusammenstellung sozialwissenschaftlicher Items und Skalen.

Nickerson, R. S. (1998). 'Confirmation bias: A ubiquitous phenomenon in many guises'. Review of General Psychology, 2, 175-220.

Noll, H.-H. (1996). Ungleichheit der Lebenslagen und ihre Legitimation im Transformationsprozeß: Fakten, Perzeptionen und Bewertungen. Paper presented at the Kongress der Deutschen Gesellschaft für Soziologie.

Noll, H.-H. and Roberts, L. W. (2003). 'The legitimacy of inequality on both sides of the Atlantic. A comparative analysis of attitudes in Canada and Germany'. The Tocqueville Review, 24, 153-89.

Obama, B. (2016). State of the Union address. Available at: https://www.whitehouse.gov/thepress-office/2016/01/12/remarks-president-barack-obama---prepared-delivery-stateunion-address [accessed 28 March 2016].

Okhuysen, G. and Bonardi, J.-P. (2011). 'The challenges of theory building through the combination of lenses'. Academy of Management Review, 36, 6-11.

Patton, D. F. (2011). 'Annus mirabilis: 1989 and German Unification'. In Walser Smith, H. (Ed.), The Oxford handbook of modern German history. Oxford: Oxford University Press 753-74.

Pew Research Center. (2014). Inequality seen as major challenge. Available at: http://www.pewglobal.org/2014/10/09/emerging-and-developing-economies-muchmore-optimistic-than-rich-countries-about-the-future/inequality-11/ [accessed 30 March 2016].

Pickett, K. E. and Wilkinson, R. G. (2015). 'Income inequality and health: A causal review'. Social Science \& Medicine, 128, 316-26.

Piketty, T. (2014). Capital in the Twenty-First Century. Cambridge: Harvard University Press.

Powell, W. W. and Colyvas, J. A. (2008). 'Microfoundations of institutional theory'. In Greenwood, R., Oliver, C., Sahlin, K. and Suddaby, R. (Eds.), The Sage handbook of organizational institutionalism. Los Angeles: Sage, 276-98.

Ryder, N. B. (1965). 'The cohort as a concept in the study of social change'. American Sociological Review, 30, 843-61.

Schützwohl, A. (1998). 'Surprise and schema strength'. Journal of Experimental Psychology: Learning, Memory and Cognition, 24, 1182-99.

Scott, W. R. (2008). Institutions and organizations. Thousand Oaks: Sage.

Sherif, M. and Hovland, C. (1961). Social judgment: Assimilation and contrast effects in communication and attitude change. Westport: Greenwood Press.

Shore, T. H., Tashchian, A. and Jourdan, L. (2006). 'Effects of internal and external pay comparisons on work attitudes'. Journal of Applied Social Psychology, 36, 2578-98.

Sieweke, J. (2014). 'Pierre Bourdieu in management and organization studies-A citation context analysis and discussion of contributions'. Scandinavian Journal of Management, 30, 532-43.

Sieweke, J., Köllner, B. and Süß, S. (2016). 'The relationship between employees' objective internal and external pay standing and their job performance: A within-person analysis'. Journal of Business and Psychology, forthcoming.

Stinchcombe, A. L. (1991). 'The conditions of fruitfulness of theorizing about mechanisms in social science'. Philosophy of the Social Sciences, 21, 367-88.

Stryker, R. (1994). 'Rules, resources, and legitimacy processes: Some implications for social conflict, order, and change'. American Journal of Sociology, 99, 847-910.

Suchman, M. C. (1995). 'Managing legitimacy: Strategic and institutional approaches'. Academy of Management Review, 20, 571-610. 
Suddaby, R. (2010). 'Challenges for institutional theory'. Journal of Management Inquiry, 19, 14-20.

Suddaby, R., Bitektine, A. and Haack, P. (2017). 'Legitimacy'. Academy of Management Annals, 11, 451-78.

Suddaby, R. and Greenwood, R. (2005). 'Rhetorical strategies of legitimacy'. Administrative Science Quarterly, 50, 35-67.

Taber, C. S. and Lodge, M. (2006). 'Motivated skepticism in the evaluation of political beliefs'. American Journal of Political Science, 50, 755-69.

The Economist. (2016). The new wave. Available at: http://www.economist.com/news/booksand-arts/21695853-surprisingly-little-known-about-causes-inequality-serbianamerican-economist [accessed 03 April 2016].

The Guardian. (2016). Richest 62 people as wealthy as half of world's population, says Oxfam. Available at: http://www.theguardian.com/business/2016/jan/18/richest-62billionaires-wealthy-half-world-population-combined [accessed 5 April 2016].

Thornton, P. H., Ocasio, W. and Lounsbury, M. (2012). The institutional logics perspective A new approach to culture, structure, and process. Oxford: Oxford University Press.

Tilcsik, A. (2010). 'From ritual to reality: Demography, ideology, and decoupling in a postcommunist government agency'. Academy of Management Journal, 53, 1474-98.

Tost, L. P. (2011). 'An integrative model of legitimacy judgments'. Academy of Management Review, 36, 686-710.

Trump, K.-S. (2017). 'Income inequality influences perceptions of legitimate income differences'. British Journal of Political Science.

Tyler, T. R. (2006). 'Psychological perspectives on legitimacy and legitimation'. Annual Review of Psychology, 57, 375-400.

van der Toorn, J., Berkics, M. and Jost, J. T. (2010). 'System justification, satisfaction, and perceptions of fairness and typicality at work: A cross-system comparison involving the US and Hungary'. Social Justice Research, 23, 189-210.

Verbeek, M. and Nijman, T. (1992). 'Can cohort data be treated as genuine panel data?'. Empirical Economics, 17, 9-23.

Voronov, M. and Vince, R. (2012). 'Integrating emotions into the analysis of institutional work'. Academy of Management Review, 37, 58-81.

Walker, H. A., Rogers, L. and Zelditch, M. (1988). 'Legitimacy and collective action: A research note'. Social Forces, 67, 216-28.

Walker, H. A., Thomas, G. M. and Zelditch, M. (1986). 'Legitimation, endorsement, and stability'. Social Forces, 64, 620-43.

Wang, S.-H. and Morris, R. G. M. (2010). 'Hippocampal-neocortical interactions in memory formation, consolidation, and reconsolidation'. Annual Review of Psychology, 61, 4979.

Wu, X. (2009). 'Income inequality and distributive justice: A comparative analysis of mainland China and Hong Kong'. The China Quarterly, 1033-52.

Yoon, J. and Thye, S. (2011). 'A theoretical model and new test of managerial legitimacy in work teams'. Social Forces, 90, 639-59.

Zelditch, M. (2001a). 'Processes of legitimation: Recent developments and new directions'. Social Psychology Quarterly, 64, 4-17.

Zelditch, M. (2001b). 'Theories of legitimacy'. In Jost, J. T. and Major, B. (Eds.), The psychology of legitimacy: Emerging perspectives on ideology, justice, and intergroup relations. Cambridge: Cambridge University Press, 33-53.

Zelditch, M. (2004). 'Institutional effects on the stability of organizational authority'. Research in the Sociology of Organizations, 22, 25-48.

Zelditch, M. and Walker, H. A. (1984). 'Legitimacy and the stability of authority'. Advances in Group Processes, 1, 1-25. 
Zimmerman, M. A. and Zeitz, G. J. (2002). 'Beyond survival: Achieving new venture growth by building legitimacy'. Academy of Management Review, 27, 414-31. 
Table I

Correlations and Descriptive Statistics ${ }^{\mathrm{a}}$

\begin{tabular}{|c|c|c|c|c|c|c|c|c|c|c|c|c|c|c|}
\hline & Variables & Mean & SD & 1 & 2 & 3 & 4 & 5 & 6 & 7 & 8 & 9 & 10 & 11 \\
\hline 1. & Belief in the legitimacy of inequality & 2.36 & 0.70 & & & & & & & & & & & \\
\hline 2. & Gender $(1=$ female $)$ & 0.51 & 0.50 & -0.08 & & & & & & & & & & \\
\hline 3. & Income $^{\mathrm{b}}$ & 7.46 & 0.63 & 0.11 & -0.12 & & & & & & & & & \\
\hline 5. & Unemployed ( 1 = yes) & 0.07 & 0.25 & -0.10 & -0.00 & -0.24 & -0.29 & & & & & & & \\
\hline 6. & Age & 49.45 & 16.80 & 0.11 & 0.04 & -0.11 & 0.08 & -0.11 & & & & & & \\
\hline 7. & Low level of education ( $1=$ yes $)$ & 0.42 & 0.49 & 0.11 & 0.02 & -0.27 & -0.11 & 0.01 & 0.36 & & & & & \\
\hline 8. & Medium level of education ( 1 = yes) & 0.33 & 0.47 & -0.07 & 0.04 & 0.05 & -0.03 & 0.06 & -0.23 & -0.61 & & & & \\
\hline 10. & Lived in the GDR prior to 1990 ( 1 = yes) & 0.43 & 0.50 & -0.22 & 0.02 & -0.25 & -0.12 & 0.15 & 0.06 & -0.10 & 0.18 & -0.13 & & \\
\hline 11. & Years spent in the GDR/FRG prior to 1990 & 32.41 & 12.53 & 0.10 & 0.02 & -0.18 & 0.05 & -0.06 & 0.85 & 0.37 & -0.19 & 0.03 & 0.08 & \\
\hline 12. & Years spent in Germany after 1990 & 11.88 & 7.55 & 0.01 & -0.02 & 0.34 & -0.05 & -0.04 & 0.14 & -0.14 & 0.02 & -0.00 & -0.07 & -0.27 \\
\hline
\end{tabular}

, 312 ; all $\mathrm{r} \geq|0.02|$ are significant at $\mathrm{p} \leq 0.05$; two-tailed tests.

${ }^{\mathrm{b}}$ Logarithmized. 
TABLE II

Results of OLS Analyses ${ }^{\mathrm{a}}$

\begin{tabular}{|c|c|c|c|c|}
\hline Variables & Hypothesis & Model 1 & Model 2 & Model 3 \\
\hline \multicolumn{5}{|c|}{ Dependent variable: Belief in the legitimacy of inequality } \\
\hline \multicolumn{5}{|l|}{ Control variables } \\
\hline Intercept & & $2.39^{* * *}(0.02)$ & $2.49^{* * *}(0.09)$ & $2.57^{* * *}(0.02)$ \\
\hline Gender (1 = female) & & $-0.09^{* * *}(0.01)$ & $-0.09^{* * *}(0.01)$ & $-0.09^{* * *}(0.01)$ \\
\hline Income $^{\mathrm{b}}$ & & $0.08^{* * *}(0.01)$ & $0.04^{* * *}(0.01)$ & $0.03^{* *}(0.01)$ \\
\hline Financial situation & & $0.12^{* * *}(0.01)$ & $0.12^{* * *}(0.01)$ & $0.12^{* * *}(0.01)$ \\
\hline Unemployed (1 = yes) & & $-0.07^{* *}(0.02)$ & $-0.01(0.02)$ & $-0.02(0.02)$ \\
\hline Age & & $0.00^{* * *}(0.00)$ & $0.00^{* * *}(0.00)$ & $0.00^{* * *}(0.00)$ \\
\hline Low level of education (1 = yes) & & $0.17^{* * *}(0.02)$ & $0.14^{* * *}(0.02)$ & $0.14^{* * *}(0.02)$ \\
\hline Medium level of education (1 = yes) & & $0.04^{* *}(0.01)$ & $0.07^{* * *}(0.02)$ & $0.07^{* * *}(0.02)$ \\
\hline Political view & & $0.07^{* * *}(0.00)$ & $0.06^{* * *}(0.00)$ & $0.06^{* * *}(0.00)$ \\
\hline Year dummies included & & Yes & Yes & Yes \\
\hline \multicolumn{5}{|l|}{ Independent variables } \\
\hline Lived in the GDR prior to 1990 (1 = yes) & & & $-0.31^{* * *}(0.01)$ & $-0.27^{* * *}(0.01)$ \\
\hline Years spent in the GDR/FRG prior to 1990 & & & $0.00(0.00)$ & $0.00(0.00)$ \\
\hline Years spent in Germany after 1990 & & & $-0.01^{* * *}(0.00)$ & $-0.01^{* * *}(0.00)$ \\
\hline \multicolumn{5}{|l|}{ Interaction effects } \\
\hline $\begin{array}{l}\text { Lived in the GDR prior to } 1990 \mathrm{x} \text { Years } \\
\text { spent in Germany after } 1990\end{array}$ & $\mathrm{H} 1$ & & $0.02^{* * *}(0.00)$ & $0.01^{* * *}(0.00)$ \\
\hline $\begin{array}{l}\text { Lived in the GDR prior to } 1990 \times \text { Years } \\
\text { spent in the GDR/FRG prior to } 1990\end{array}$ & H3 & & $-0.01^{* * *}(0.00)$ & $-0.01^{* * *}(0.00)$ \\
\hline $\begin{array}{l}\text { Years spent in the GDR/FRG prior to } 1990 \\
\text { x Years spent in Germany after } 1990\end{array}$ & & & & $0.0002^{*}(0.0001)$ \\
\hline $\begin{array}{l}\text { Lived in the GDR prior to } 1990 \mathrm{x} \text { Years } \\
\text { spent in the GDR/FRG prior to } 1990 \mathrm{x} \\
\text { Years spent in Germany after } 1990\end{array}$ & $\mathrm{H} 2$ & & & $-0.0002^{*}(0.0001)$ \\
\hline $\mathbf{F}$ & & $114.29^{* * *}$ & $124.46^{* * *}$ & $117.30^{* * *}$ \\
\hline Adjusted R-squared & & 0.105 & 0.146 & 0.143 \\
\hline $\mathbf{N}$ & & 13,812 & 13,812 & 13,812 \\
\hline
\end{tabular}

Note: Unstandardized regression coefficients are shown with robust standard errors in parenthesis.

${ }^{\mathrm{a}+} \mathrm{p} \leq 0.10 ;{ }^{*} \mathrm{p} \leq 0.05 ;{ }^{* *} \mathrm{p} \leq 0.01 ; * * * \mathrm{p} \leq 0.001$; two-tailed tests.

${ }^{\mathrm{b}}$ Logarithmized. 


\section{FIGURE 1}

Changes in Beliefs About the Legitimacy of Inequality Between 1991 and 2014

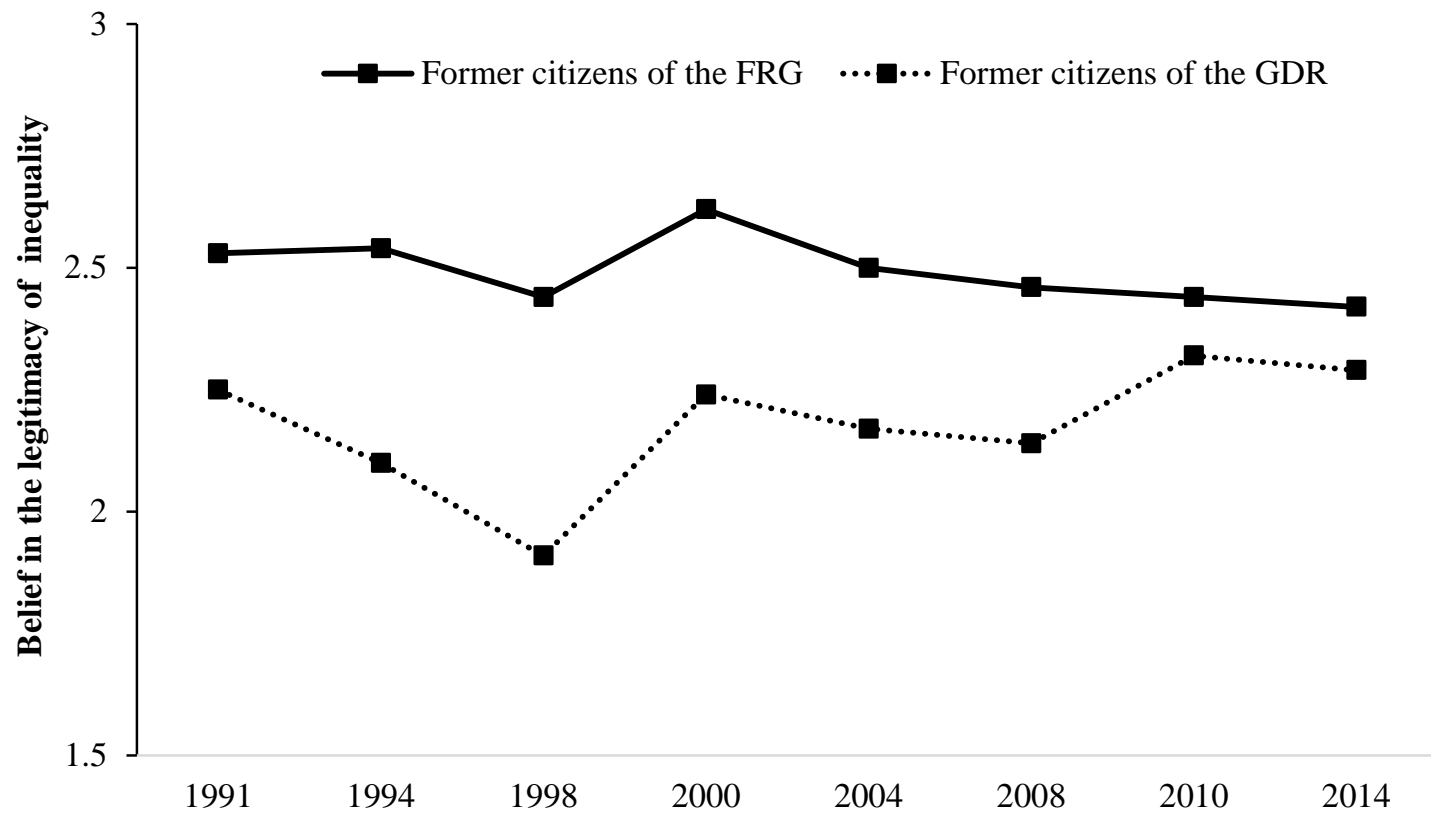

FIGURE 2

Interaction Between the Number of Years Spent in Germany After 1990 and

Whether the Respondents Had Lived in the FRG or GDR Prior to 1990

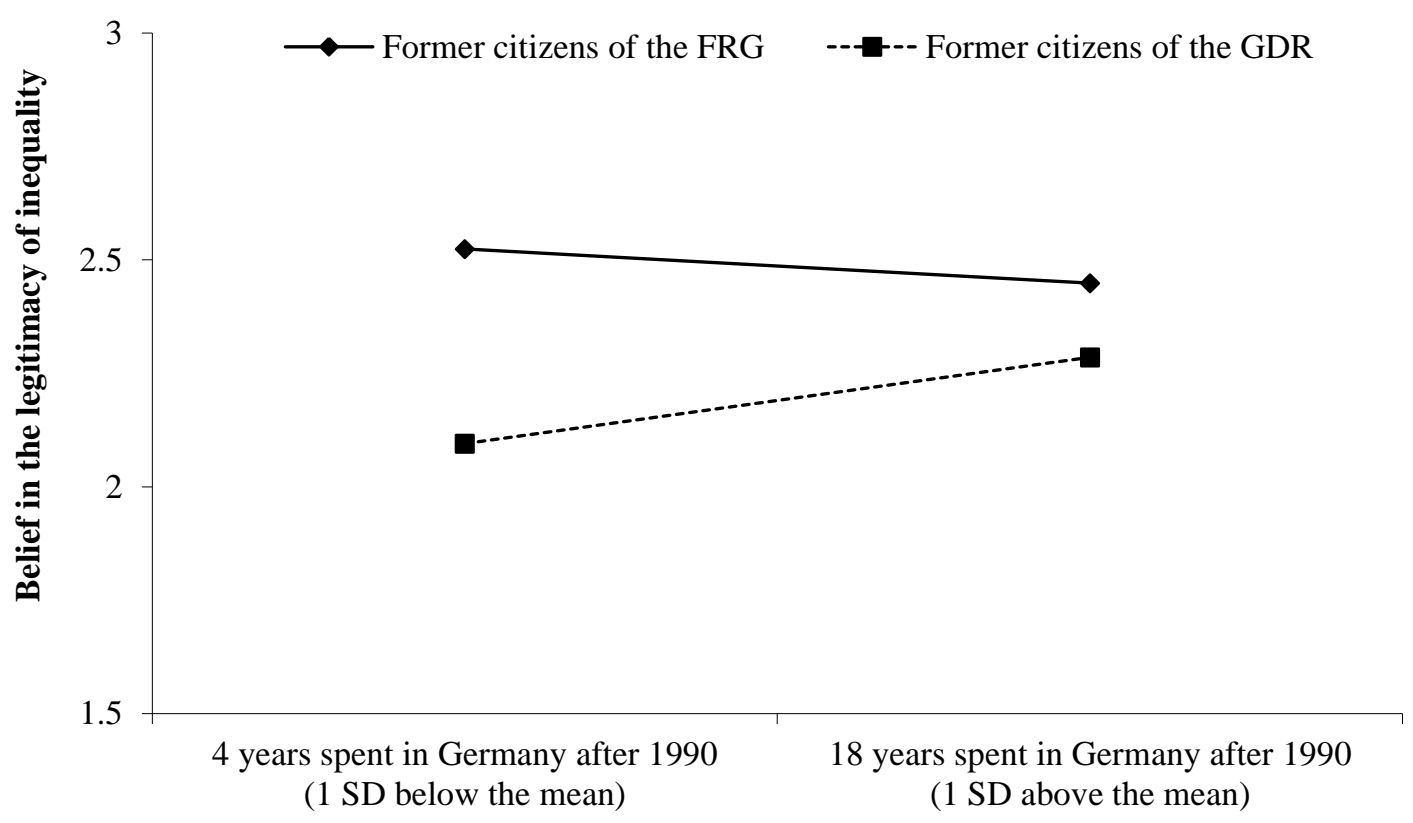




\section{FIGURE 3}

Interaction Between the Number of Years Spent in the GDR/FRG Prior to 1990, the Number of Years Spent in Germany After 1990, and Whether the Respondents

Had Lived in the FRG or GDR Prior to 1990

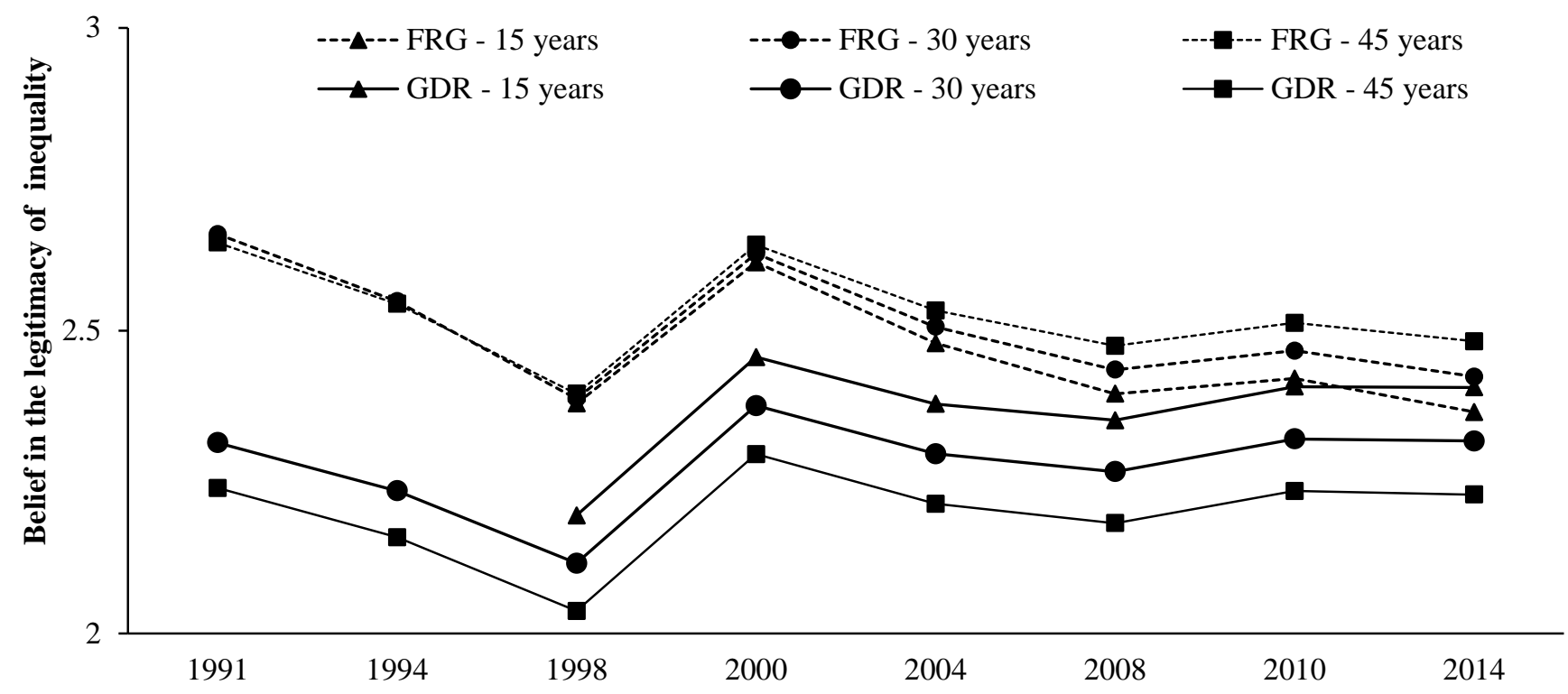

FIGURE 4

Interaction Between the Number of Years Spent in the GDR/FRG Prior to 1990 and Whether the Respondents Had Lived in the FRG or GDR Prior to 1990

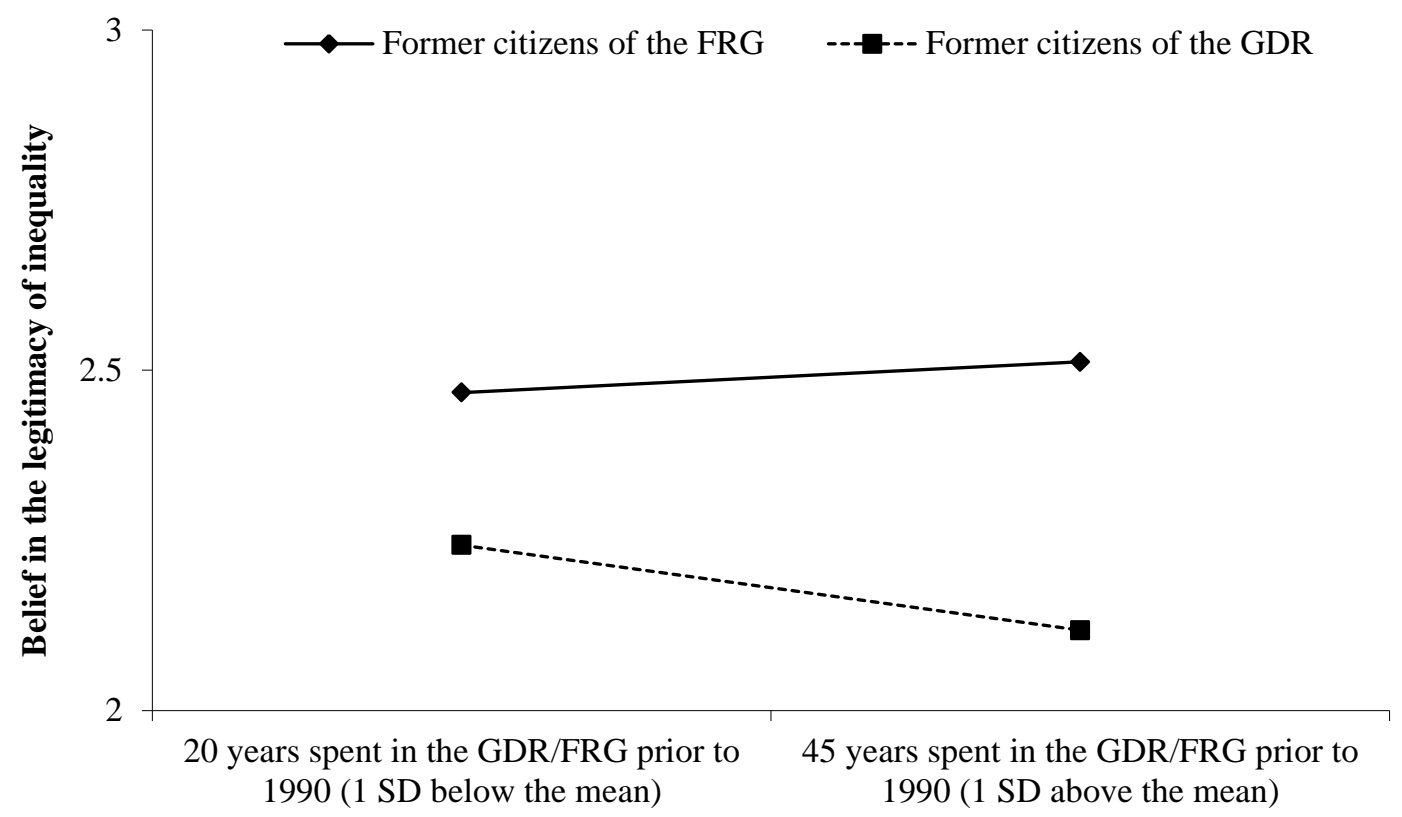

